\title{
Circular Materials and Circular Design-Review on Challenges Towards Sustainable Manufacturing and Recycling
}

\author{
Ludovic F. Dumée ${ }^{1,2,3}$ iD \\ Received: 30 March 2021 / Accepted: 16 June 2021 / Published online: 26 June 2021 \\ (C) The Author(s), under exclusive licence to Springer Nature Switzerland AG 2021
}

\begin{abstract}
The selection and engineering of materials is a critical component towards the development of a circular economy model. The redesign of both consumer commodity goods and advanced products may not only require engineering feats in terms of advanced structures but also the implementation of safer and more facile to recycle materials. Although such endeavours include the engineering of goods generated from clever components assemblies, easier to dismantle and separate, new avenues to move beyond planned obsolescence towards triggered obsolescence, whereby materials may degrade on command, is required. Circular Materials must be designed to enable complete recycling of materials and novel synthesis strategies free from toxic precursors or by-products to regenerate raw materials. Circular materials shall therefore be processed first at the local level for local needs. Key supply-chain challenges arising from the COVID-19 lockdowns have further stressed the relevance of this issue and the need to have develop well dispatched geographically manufacturing hubs. Changes towards Circular Materials considerations will depend on the development of repurposing and recycling platforms as well as from the rebirth of delocalized manufacturing capabilities. This chapter will present current solutions to develop sustainable materials engineering strategies and focus on greener fabrication and recycling routes. Focus on smarter designs and life-cycle analysis will reflect on how Circular Design of materials may contribute to the Circular Economy.
\end{abstract}

Keywords Circular design · Materials reengineering $\cdot$ Rresource recovery $\cdot$ Recycling · Repurposing · Circular materials

Ludovic F. Dumée

ludovic.dumee@ku.ac.ae

1 Khalifa University, Department of Chemical Engineering, Abu Dhabi, United Arab Emirates

2 Research and Innovation Centre on CO2 and Hydrogen, Khalifa University, Abu Dhabi, United Arab Emirates

3 Center for Membrane and Advanced Water Technology, Khalifa University, Abu Dhabi, United Arab Emirates 


\section{Introduction}

Consumer awareness with regards to the need to develop new manufacturing and repurposing strategies for commodity materials, have risen extensively over the past 10 years $[1,2]$. The concept of Circular Economy, initially considered as a utopia, is emerging as the only manageable strategy to reduce pressure on increasingly scarce resources and to limit the generation of waste products. Circular Economy strategies, focused on Circular Materials and design, must however be implemented in rationale phases to shift from traditional production strategies [3].

Product life cycle strategies utilised over the course of a Linear Economy (LE) product development rely on a set of identified stages across the lifespan of the commodity [4]. Such stages within a LE strategy including the following (1) development, (2) introduction, (3) growth, (4) maturity, (5) decline, and (6) disposal of the materials [5, 6]. Tools available to companies to develop new products include market research and competitor analysis within the development stage, which are performed to crystallise the potential growth for the product and to build relevant business cases to validate the products acceptability by the consumers. During the introduction phase, the product is promoted to develop public awareness about the upcoming product and this marketing exercise spans across a range of media and diffusion mechanisms to promote the key criteria of interest to the customer, often early adopters, the performance of the product. The growth stage occurs when the market share of the product becomes visible above the noise of its competitors and if a product completes the introduction and growth stages successfully, it will progressively reach the maturity stage. During this maturity stage, typically and hopefully the longest over the lifetime of a product, dissemination of the product grows at a very fast rate, prior to gradually plateauing. The need for any commercialised product to overcome the risks of market obsolescence and decline are achieved through differentiation of the product from its competitors or by upgrading further the product to account for customer feedbacks. At the end of its lifetime the product may be recycled, if considered cost-effective, or disposed and sent to landfill or for incineration. The innovation in term of performance of the product will dictate the time at which the product will enter the decline stage, leading to a reduced share market and ultimately an end of production.

This LE model has thrived for over 100 years since the inception of mass production as the leading model of our economies. The LE model therefore encompasses several design and redesign steps allowing for market penetration, adaptation to competitors and needs or demand from customers about performance [7]. Circular Design is just one extra performance criteria demanded by customers to ensure that the end of life of their products is not only predicted and controlled but sustainable. This demand, driven by customers towards more environmental fairness and concerns of sustainable growth represents a renewed awareness of mankind responsibility in the abuse of natural resource and their management. This paradigm shift in behaviour will lead markets over the decades to come and force manufacturers to develop innovative solutions to loop their materials manufacturing to recycling or repurposing strategies $[5,8]$.

Although often considered as a brake to competitively from a profit point of view, redesigning materials for a $\mathrm{CE}$ does not necessarily require extensive alteration to initial designs [9]. Examples of competitor products on the market allowing for facile disassembly leading to the recovery of parts, which can be readily recycled or else repurposed are nowadays common. In parallel, the application of various materials grades allowing for cost-competitive recycling strategies has often hindered the development of circular recycling 
pathways from the mismatch of the various grades of materials recovered within recycling stations [7]. The economy of scale achieved by reducing or altering the quality of raw products used may indeed affect the ability to recover materials and render recycling efforts vain or inefficient [8].

The origin of the barriers preventing strategies towards the development of the circular design of materials will be discussed in this review [10]. A strong focus will be put on discussing the rationalisation of materials and on present arguments towards awareness of the finite nature of resources used for any product manufacturing, as well as to the design of the system to facilitate recovery of components and individual materials [11]. It is globally acknowledged that shifting the view on materials, at the corporate, governmental and consumer levels, from waste perception to a resource valorisation would support industrial prosperity, environmental sustainability as well as personal and societal fulfilment. Currently, the value and potential of these materials is immediately diminished leading regulatory bodies to handle them as nonvaluable materials [12]. A paradigm both from a societal and industrial point of view will be reached when such products, representing resources are redefined to be intelligible to the various stakeholders in terms of the design, manufacturing, and recycling chains. The objectives of any CE approach are to enhance the lifetime of products, facilitate repurposing of items and divert waste materials from landfill back to production lines [13]. On the long term, such approaches will lead to further rationale design of products, which may be easily dismantled into core parts for repurposing or recycling. However, on the short term, redefining wastes as resources to optimise their recovery shall be a priority.

This paper aims at acting both as a high level critical review and a piece of opinion to support circular design and circular materials strategies, and will first present the barrier and enablers of circular design to identify recurring challenges preventing its implementation. The discussion will then be focused on the various classes of materials resources available and requiring circular redesign or recycling. A critical discussion with examples on flaws in their designs preventing their facile repurposing or recycling will be presented prior to assessing strategic routes to favour a circular design approach of circular materials.

\section{Enablers and Barriers to Circular Designs and Engineering}

Altering the visibility of the end-of-life of products end is critical to overcome the complex economic, environmental, and social challenges faced by the development of a CE strategy $[11,14]$. A rapid transition from the current status quo of linear business models to circular approaches is required towards global sustainability and to reduce pressure on natural resources. The implementation of innovative circular design and production strategies will not only benefit society but also offer opportunities for companies by positively affect economic growth, reducing negative impact on the environment, renewing the job market through innovation and helping improve the image and recognition linked to their core values and missions. A number of fundamental enablers and barriers to both innovation and implementation of innovation must be considered to enable this shift.

On the one hand, at the company level, enablers may support business changes and reorientations [5, 8]. High-level commitments, with long-term business engagement over 10-30 years, and visionary perspectives are critical to such model alterations. The transformative implementation of top-down strategies, as opposed to conventional bottom-up manufacturing approaches is favouring long-term planning and investment, which may 
facilitate decision making for top management to transition to circular approaches [15]. Simultaneously, personal drive and attitudes of personnel to become involved with circular philosophies must be encouraged through proper communication on the renewed vision of the enterprise and internal marketing. Such empowerment of staff, at the societal and engineering level through soft-skills teaching and towards targeted actions developments will support longterm acceptance and engagement [16]. This approach shall provide a sense of purpose, motivating employees who may realise better the competitiveness of their areas, thus ultimately facilitating attraction and retainment of talents [17]. Such engagement strategies will profit the companies through productivity increase across more vibrant and stimulating environments led and committed by their associates and employees. Additionally, the promise of enhanced competitiveness will help maintain market shares and revenues in an ever more competitive environment. The perception of the company, shown to care and being considerate to its customers, will be benefited leading to competitive advantages over linear or conventional businesses. This approach will be further enabled across innovative ecosystems, favouring partnerships, and collaboration of both stakeholders and competitors [8, 17]. In addition, the standardisation of requirements across the value chain, through more stringent product certifications and calculations, such as life cycle assessments will allow to track efficiently sustainability. The development of clear standards and behavioural charts will support rapid assessements of the products manufacturing pathways and subsequent recycling or repurposing solutions. Such stewardship will become the norm to facilitate the identification of socially responsible suppliers or service providers and offer versatile trains of solutions to the redesign and remanufacturing in favour of circular models.

On the other hand, from a financial level point of view, several barriers must be overcome to enable a CE strategy. First, the financing of new business models coupled with taxation systems must be supported. Business transformations come at costs and would require appropriate transition periods to adjust to the various required or adopted models. Upfront, sensible, and progressive, cash investments required for business innovation will contribute to the high cost of implementing circular models. These costs include the research of usage of secondary products and raw materials, as opposed to the often higher grade virgin resources at lower cost as well as current global taxation and pricing systems, which rewards linear models rather than circular ones. Altering subsidies to fossil fuels, revising policies on long-range transport of materials and goods and manufacturing development or redevelopment in a sustainable economy must be supported [18-21]. The development of schemes towards lower energy costs but also more stringent environmental responsibilities for manufacturers to care for wastes shall be implemented $[22,23]$. Particularly, alternative routes to valorise the recycling of materials and resources must also be sought to standardise the quality and potential of these regenerated resources based on key performance criteria [24]. Economy of scale may only be achieved if quality controls of these resources produced are indeed certified by regulatory bodies and benchmarked by raw materials producers themselves [12]. A secondary raw material market will emerge and progressively integrate the main virgin material market to avoid questionable qualities to be circulated across markets and to facilitate the transformation [11]. Such endeavours will be achieved through a mix of favourable taxation or rebate schemes, whereby local sourcing of products, from recycling or mixed recycling materials are encouraged or rendered mandatory. In addition, the perceived lack of consumer demand may often limit push for innovation and the emergence of eco-designs supporting the semiautomated or automated dismantling of products may be supported by popular demand from the market base. 
A key challenge however stands with the common lack of infrastructures to adequately support this transition towards circularity. This lack of capabilities, at the research, recycling and engineering levels, to develop cost-effective and yet low energy foot-print recovery solutions are often, and very unfortunately, coupled to lack of local manufacturing capabilities [11]. The decades long approach consisting in locally burying waste or shipping them to processing platforms oversea, where these materials were often either burnt or buried, is however over [20]. Key barriers to the development of circular strategies is progressively lifting from public, academic and industry realisation of the risks associated with single or centralised global supply chains. Supply challenges observed during the COVID-19 pandemic situation, and global lockdowns of entire countries, has clearly exacerbated this challenge and it is likely that protective national policies will secure alternative supply chains in the very near future [25] or shift, from public pressure, to locally sourced and produced strategic products. Large manufacturing goods net-importers, such as developed countries, must rethink their goods import, and wastes export strategies to ensure that the volumes of secondary raw resources generated are manageable by their local manufacturing and recycling networks. Risks of overheating local materials markets with offer whilst overcooling new manufacturing hubs with demand will lead to unsustainable materials and commodity prices volatility. The redeployment of specialty manufacturing of goods is therefore a prerequisite and must be supported by local, national, and supranational authorities [26, 27].

\section{Challenges With Circular Raw Materials Generation}

The recycling of products is the most necessary solution to the development of focused raw material markets $[24,28]$. Recycled materials may be categorised across a range of areas including liquid, gaseous, and solid resources, which resources may be directly generated from the goods as a whole or a component, or indirectly if extracted from a mix or composite materials. Some resources may also be indirectly related to the recycling and repurposing upon cleaning, scrubbing or extraction procedures generating waste streams for further processing.

\section{Gaseous Materials}

Gaseous wastes represent a largely untapped resource and may be directly produced during repurposing or generated from the thermal or biological decomposition of materials [22]. The capture of toxic gases must be a priority within this overall resource treatment process, which may be generated from the decomposition of materials during recovery or storage such as in landfills, but also from specific processes required to extract other valuable materials and to increase their value. Although valuable gases such as methane or ammonia may be generated for energy production [29] during such processes, toxic gases including greenhouse and fluorinated gases may also be formed. The valorisation of methane or ammonia as new fuels has great potential and shall be evaluated fully in such approach, in line with current biogas generation strategies [30]. The production of biogas is economically viable and has been implemented across a range of waste-to-energy operation units as well as for specific remediation of biocontaminants. The risks arising from biogas utilisation, in terms of greenhouse gas emissions, must however be considered carefully in the LCA of the process and materials $[31,32]$. The conversion of gases otherwise typically considered finite waste materials, such as carbon dioxide, to small molecular weight chemicals, and fuels also represents a valuable route 
to the circular design of the economy [33]. Such strategies shall be sustained with renewable energies inputs and across a range of manufacturing scales [34]. The potential of such waste gases to represent a feedstock for other applications, including their direct atmosphere extraction, will be a key milestone in the achievement of circular materials fluxes. The development of circular materials will be enabled by the development of holistic technologies ensuring safe disposal and recovery of such gases.

\section{Liquid Materials}

Liquid resources generated from manufacturing or recycling activities include water and organic solvents. Resource recovery from dismantling or decomposing products may also generate brines or solutes of high value requiring further purification treatments [35]. The toxicity and fate of such fluids, liquids or slurries, shall be considered to limit environmental impact on ecosystems as well as a complexification of the recycling and circular strategy implementation. The development of nonorganic solvent alternatives or the regeneration of these and solvent should be prioritised to reduce the footprint and cost of the recycling process and enable circular manufacturing pathways [36, 37]. Enhancing the water recovery and alternative water reuse strategies is also an integral aspect of Circular Material strategies.

Although such recoveries may be achieved with novel and more specific waste water treatment plant operations, involving bioreactors, membrane systems, adsorbents, as well as sedimentation and distillation facilities, treating waste at the source of production is by far a much more advantageous and long-term solution. Strategies involving zero-liquid discharge for instance are evolving quickly and offer routes to reduce the final volumes of waste materials by several folds, generating resource streams for direct reuse within manufacturing processes or with real monetary value. The recycling of liquid waste from spent batteries is one of such examples and represents an extremely relevant industrial challenge [38]. The scarcity of many rare earth, alkali, and heavy metals constituents of batteries are typically processed through hydrometallurgical solutions. The recovery of such valuable resources shall be performed not only of economic value but represents a turning point from an environmental aspect given the extreme fast rate of usage and production of battery materials. The volumes of e-waste materials and batteries particularly generated yearly and the forecast expansion of battery technologies, for transport or storage of energy, will require solutions to facilitate their processing $[39,40]$. Although this point is significant, it will not be elaborated further since out of scope. The development of sustainable extraction technologies, enabling speciation, and product generation, such as specific salts or solvent mixtures for direct reuse, offering lower carbon footprint and requiring lower operating and capital costs are required.

\section{Solid Materials}

Solid materials represent more valuable commodities for the manufacturing industries and include metals, polymers, ceramics, composite structures, and organics.

Organic materials, generated from biodegradable materials including food scraps or biosourced waste materials, can be efficiently composted and valorised [41]. Such materials, unless contaminated with nonbiodegradable waste, such as metals or plastics, do not represent a great difficulty in terms of repurposing. Compost may be used for agriculture or landscaping as soil regeneration strategies making such products attractive and low-cost to produce. Contamination with other materials, mixed during initial material design or recycling 
represents however a challenge and components such as labels or coatings shall be redesigned to be equally biodegradable. An example includes basic food packaging or coffee cups and take-away utensils, which can produced from premium recycled and recyclable materials. Such packaging materials however often include insulating layers made of oil-sourced polymeric materials and sometimes inorganic materials used as part of dyes or pigments for their finishing [42]. Such contamination will affect bacteria bed used during bioreactor operations detrimentally. The breakoff of plastic layers into microplastics will also represent a major challenge and these microplastics shall remain present in the soil materials generated being mixed with fresh soil and thus spreading microplastics contamination [43, 44]. Such contaminations are not well studied to date and evaluated to date but represent a challenge to overcome. Routes to tackle these issues are therefore to redesign at the source packaging materials by banning nonbiodegradable materials. A main challenge also comes from the lack of generalised definition of biodegradability, which is often abused from a marketing point of view. The lack of legal status and standards for most biodegradable labels and regarding the true meaning of biodegradability of materials allows manufacturers to develop their own, often irreproducible tests and data-sets. A number of inappropriately performed advertisement campaigns suggested that series of plastic bags made from mixed materials, biosourced and synthetic polymers, where biodegradable since the materials disappeared if buried into certain types of soils when exposed to proper acidity conditions and in presence of specific bacteria, generating the right enzymes to degrade one of the components of the materials. The typical example of plastic bags is clear and it was shown that plastic bags labelled biodegradable would fragment, leaving microplastics of synthetic polymers. Other examples of biodegradable plastics bags, if tested in different soil compositions and conditions, were found to not degrade after over 10 times the duration claimed by the manufacturer. Such examples are multiple and this concept of waste to compost must be carefully considered to prevent pollution of arable soils and transfer of plastic pollution to pristine lands.

Ceramics, such as glass fines, porcelain or stone-sourced products are not a major challenge if not mixed with metals or coated with polymeric materials [45]. Most ceramics may be crushed down to particulate levels and reprocessed as additives for civil engineering, technical ceramics, or second grade glassware manufacturing [46]. Current technologies used across sorting facilities are able to discriminate based on composition or colour at levels around 70$90 \%$, making the recovery of single strain of materials and their valorisation relatively simple and cost-competitive [47]. The sorting of the remaining 10-30\% represents however a key technical challenge since various mixed materials such as paper, biological items including bones, plastics or metals are present in the form of adhesive, labels, tags, decoration layers or caps, to name a few. The removal of these contaminants is extremely difficult since either strongly bonded to the surface of the ceramics or very well mixed with these glass fines. The colour of glass is typically achieved upon addition of metal dopants within the silica matrix and mixing crushed glass powders of different colours for repurposing will alter the ultimate colour of the material, whilst extracting the metal from the silica powder hardly manageable at industrial scale. Similarly, paints used on ceramics are also often metal-based dyes [45] and their removal is rendered difficult due to extra surface finishes or coatings, which may be polymeric or ceramic to protect the patterns. Chemical or thermal etching may be required to remove these additives, which will generate liquid or gaseous waste streams, again containing valuable resources $[46,47]$. The design of better sorting technologies allowing for higher recovery of consistent materials is therefore a priority whilst the redesigning of surface finishes 
and bulk additives to render colour or texture more sustainable should be rethought to prevent the generation of undesirable mixed waste materials, typically ending up in landfill.

Metal materials found in bulk parts are typically easier to recover and valorise. The processing steps required at high temperatures facilitate elimination of organic or polymeric contamination [48] but the presence of ceramics as anticorrosion coatings or as friction controllers may again affect the final mix purity. The very large bulk of produced metal parts will be made of stainless steel, copper and its alloys, as well as aluminium and titanium. Metal are typically much easier to recycle compared to polymeric or ceramic materials due to the broad range of metal grades used and available in engineering and manufacturing. The recycling of aluminium or stainless steel are examples of this ability to recycle metals despite the need for chemical treatments to reduce or remove oxides and the energy penalty arising from heat treatments required for melting and ingots generation. The recyclability of metals is also not has much as a challenge as polymeric materials, which can only be recycled so many times without degrading the molecular structure of the polymer (depolymerizing or overpolymerising for instance) and most metals, unless again oxidised or contaminated during their operation as a product or recycling may be recast nearly indefinitely. Separating metals from alloys is rarely done since the composition of the materials developed may be adjusted based on elemental analysis of the recovered materials. The recovery of solid metal from composite materials however represents a key challenge to be solved since energy-demanding, whilst the sorting of metals at the source is equally difficult, with the exception to ferromagnetic materials extraction from non-ferromagnetic materials, which is well mastered [49]. The sorting of metals such as aluminium or copper from titanium, becoming increasingly used in high value structural materials are very challenging and must involve selective separative steps and such metallurgical, electrochemical or physical approaches have been well developed and work at scale [50]. Metals do not therefore represent a key challenge and valorisation is nonetheless dependant on energy inputs required to deconstruct alloys into single metallic species.

Polymeric materials and commodity plastics however represent a challenge due to the wider types of polymers generated [51]. Changes in polymer contents or molecular weights may greatly affect the quality of the recycled products as well as the reproducibility of the recycling process. Polymers hold together through specific covalent bonds and most commercial polymers are either silicone or carbon based, thus requiring specific polymerisation to generate long range order products. The polymerisation conditions of the monomers, building blocks towards any polymeric materials, will dictate the properties of the final polymers formed [52]. Polymers are extremely sensitive to weathering including potentially humidity uptake and sunlight irradiation and such stress may shorten the polymeric chains, reducing the molecular weight of the materials and thus the polymer mechanical properties or permeance to gases or liquids. Slight chemical alterations may also affect the adsorption of contaminants, including organic or inorganic, which further increases the complexity of the recycling process. Polymeric materials separation may be achieved by density or chemical identification, leading to relatively large volumes of mixed waste materials. The main commodity polymeric materials available in volume include high density poly(ethylene) and poly(propylene), as well as poly(ethylene terephthalate) and poly(styrene). Although these polymeric materials may be melted and pelletised to generate new raw materials [52], the thermal reprocessing affects the polymer properties detrimentally, reducing molecular weights and therefore thermomechanical properties. Fresh polymeric material can typically be recycled 8 to 10 times prior to becoming unfit for further reprocessing. Such aspects are critical to the circular economy 
scheme and redesigning polymeric materials to either make them more resilient to reprocessing or else facilitate their depolymerisation to regenerate monomers.

Composite materials represent a broad class of architectures combining various phases to benefits from the properties of each individual constituents [53]. Typically, composite materials are made of either a main matrix to which a low volume fraction of fillers are added, or through sandwich layering whereby materials are hierarchically laid and bounded on top of each other [54]. Composite materials may be homogeneous, if made of a single class of materials or heterogeneous if consisting of various materials of different nature mixed together. The complex nature of such materials make them extremely difficult to dismantle and recycle in a cost-effective manner. Examples of homogeneous composite materials in our daily lives include most packaging materials where the mechanical strength of the packaging are provided by a specific layer, whilst air barrier properties from another. Such materials are typically processed through thermal treatments and binding steps to ensure strong adhesion and cohesion of the different materials. This durability criterion renders composite materials excellent for technical applications and examples of heterogeneous composites include liners used to print labels or generate specific surface finishes applied onto most electronics devices to protect and insulate whilst remaining light and handy [55]. Electronic components and boards, phone touch screens, shop e-tags and hundreds of thousands more products also include one or several layers of metals or ceramics mixed or sandwiched within a polymer matrix $[40,49]$. Such materials are virtually impossible to recycle and only valuable metals, potentially composing the circuits or electronic parts welded / glued onto the devices can be recovered. Textile products are also great examples of apparently simple but in reality complex materials and most textile materials incorporate different types of fibres, often natural mixed with synthetic [56]. Both composite fibres, made of different polymeric materials or a polymer and additives, as well as composite textile products, whereby several types of fibres or materials are integrated together either in the form of fibre / coating or mixed matrix product may be available [57]. The remediation of these composite materials is challenging due to the significant differences in reactivity, solubility in solvents, and thermal properties [58]. The separation of such fibres, mixed to reduce the cost and improve the stability or the comfort of the garment is challenging and the focus of extensive research efforts [59]. Textile materials, including natural polymers such as cellulosic materials and synthetic materials, can however be pelletised and used as fillers into lower grade applications, such as civil engineering based materials [54]. Else they can be burnt or sent to landfill, which remains unfortunately often the only viable solution. Strategies to downscale the materials into recycled products and finding new niche or bulk applications was demonstrated for pure wool or Cashmere products in Prato, a historical textile industry township in Italy [60]. Downgrading materials however implies that the valuable resources present across their matrixes are ultimately lost. Routes to chemically etch ceramics and metals from polymers are available but are costly and tend to generate large volumes of waste liquid effluent streams requiring further processing.

The next section will discuss routes to account for such design flaws and ensure new generations of products are designed for sustainability. Manufacturers nowadays have a moral obligation, generated from customers' pressure, to develop longer lasting solutions and to ensure that products conceptualization considers the cost of manufacturing but also the repurposing, dismantling, and recycling of commodities. 


\section{Redesigning for Dismantling and Recycling}

This section provides a review of overarching strategies towards the redesign of materials to fit a circular philosophy. Technical and societal challenges to overcome will be discussed whilst case study examples, whereby day-to-day products were replaced or altered to generate circular materials, will be presented. The purpose of this section is to engage on the relevance of redesigning products in a sustainable way and a driving point for most of these case studies lies with innovation driven by market needs. The input from customers is critical and solutions must emerge from increasing environmental awareness by a bottom-up hierarchy.

Massed produced goods are not designed by considering the entire product lifetime and particularly their disposal phase. Since nowadays neither the manufacturer nor the customer are directly liable for the disposal of the products, design typically stops at the functionality level and it is critical to account for disposal strategies. Key criterion to consider should include dismantling to facilitate the recovery of most parts or pristine materials. Looking at the example of electronic touch pads, the differences between brands in terms of design are striking. Although Apple's I-pad, one of the most single brand sold touch pad, are slim and aimed at being robust and un-alterable by common customers, this design does not readily support dismantling operations. This aspect is probably well-thought to prevent intellectual property theft and avoid device hacking, which would reduce the brand value of the products rapidly over time. For this reason, I-pads are "black boxes", which are extremely difficult to recycle. Not only are all electronic pads made of composite materials formed across a range of metal/polymer/ceramic structures, but these structures are so compact that the only way to dismantle them is to nearly crush them. Some electronic touch pads manufacturers have opted for more relaxed structures, which can be opened, altered and hacked by their users or repairshops. The design phase of such items must therefore be strongly supported to have the end of life of the products in mind and to facilitate the recovery of valuable materials upon recycling or repurposing. At present, very few solutions exist to properly and sustainably recycle electronic products. The separation of the batteries, sometimes welded onto other parts, and the recovery of various boards and functionalities made of valuable metals is being explored through a number of routes including chemical and thermal treatments, which are not environmentally friendly, and routes to therefore assemble differently the materials must be considered. Most resins used for boards manufacturing are made from chemically cross-linked chemicals and are therefore close to impossible to reprocess. The major cost during recovery is however not the extraction and the separation processes, but the manpower required for extraction and sorting.

Batteries are another class of complex multi-material composite systems, which waste volumes are increasing exponentially. The performance of battery materials has improved dramatically over the past 15 years and upcoming energy storage strategies will support further performance increase in terms of lifespan, power densities and capacity. The great majority of battery technologies are composed of multiple compartments and materials arranged into tight and sealed systems to ensure optimum performance as well as leak-free and safe operation. The brines used for charge transfers within the batteries are often complex and toxic, and their varied compositions, depending on the type of battery system, make some of them prone to reactions with oxygen in air or water moisture. Novel strategies must be developed to ensure safe operation whilst facilitating the recovery of all valuable resources from the spent batteries. Such strategies are under the scrutiny of various technical and legal governmental and 
scientific bodies globally, particularly in Europe amongst the priorities of the Strategic Energy Technologies Information System (SETIS).

Another type of mass-consumed products used on a daily basis i is related to take-away cutlery and materials. The take-out way of life generates very large volumes of wastes going in the best of scenarios straight to landfill. Disposable coffee cups are an example where cardboard materials are protected with a hydrophobic polymer coating to limit hot drinks diffusion within the cellulosic material. This coating is applied upon polymer melt deposition to secure a tight and strong bond with the cardboard, rendering a robust design for the lifetime of the hot drink. The polymer layer may not however be forcibly removed once the cup is used and various chemical or heat treatments have been tried, largely unsuccessfully or through unscalable operating conditions. Designing cups without protective layers or where the layer is made of an easy to remove material represents one avenue forward and crafting disposable cups from materials which are either recyclable or compostable would be sustainable, even if requiring a product cost increase. Some products have emerged with such strategies whereby the liner is made from biodegradable materials whereby a cross-linked naturally sourced polymer is used. Recently marketed sustainable cups were shown to be processed from fruit peels, which are generated during juice processing. The peels may be dried and pelletised, with the same apparatus which produces the juice, and the pelletised materials are used for 3D printing to generate the cup in which the juice will be poured into. These peel-based cups are aimed to last for $4 \mathrm{~h}$, which is sufficient for on-the-go applications and are fully compostable.

Disposable materials are also common practise in the biomedical are for obvious health and safety aspects, leading to large volumes of generated, and contaminated single use materials. The materials are destroyed since representing a biological threat typically through pyrolysis at high temperature. The design of these consumables is typically performed to ensure maximum safety and resilience and the capacity of the products to be reused shall therefore not be a challenge provided that appropriate cleaning procedures to remove biological contaminants are put in place. Such strategies are sensitive since the presence of remaining biological contaminants would represent a great liability for practitioners or medical utensils providers. Historically however, medical equipment were primarily glass and stainless steel based which allowed for strong disinfectants to be used as well as autoclaving steps to destroy any potential pathogens. Since current disposable utensils are burnt to prevent pathogen transfers and health risks, the argument related to the cost of such treatments would therefore appear deterrent. The design of multiple usage, convenient, and resilient materials able to sustain appropriate chemical or thermal cleanings is therefore possible but the choice of materials must be carefully performed to select polymers or components able to sustain a number of cycle. Appropriate life cycle analysis may allow for the design or potentially costly to produce with yet longer lasting capabilities.

The development of global recycling and valorization strategies has been supported by several actors since the early 2000's, including companies such as WRAP and Terracycle, have been developing technical and socio-economical reports to support governmental agencies and companies in waste valorization stewardship. The mission of such not-for-profit or charitable companies is to empower customers and service providers by offering either waste to resource solutions key-in-hand or support the dismantling and recycling of complex waste materials $[61,62]$.

Although a greater number of specific examples may be provided to illustrate the need to redesign materials and structures, the market reality shall face both moral and technical 
obligations in a resource scarce future, where Circular Economy and materials engineering will dominate as a drive to reduce footprint and landfill disposal.

\section{Conclusions and Prospects}

The development of circular materials will be achieved following two parallel but yet complementary strategies. Recycling and repurposing of goods, their components and materials must be encouraged, facilitated and engineered. Advanced separation techniques supporting increasingly stringent speciation capabilities and requirements are being developed to render resource recovery cost-competitive compared to pristine resources extraction and processing. Redesigning materials with the entire life cycle of the product in mind must be carried out by manufacturers at a global scale. This aspect is as much marketing as educational since designers and engineers shall work with more drastic and complex specifications to enable this circular design. Markets and consumers are demanding such changes both from a morale perspective and a long term vision point of view. The excessive use and extraction of resources is leading to their rarefaction which will lead to increased commodities prices, detrimental to the customer and the environment. Such circular material design considerations will affect manufacturing globally and companies as well as governments must envision new policies to ensure that circular economy and approaches are considered at all stage of productions.

The development of a global strategic roadmap inclusive of current applications of circular economy strategies and policies from an industrial, governmental and societal point of view may support future perspectives and the development of such circular design and engineering strategies particularly for developing economies. Such statistics would support LCA and predictions about the usage and applicability of Circular Economy strategy to specific cases and help with stewardship development across the board for all materials recycling, repurposing, and redesigning approaches.

Acknowledgements A/Prof Dumée acknowledges the Australian Research Council for his Discovery Early Career Research 2018 Award (DECRA DE180100130) and support from Khalifa University of Science and Technology under project RC2-2019-007.

Authors' Contributions LFD: data curation and manuscript writing

Funding Not applicable.

Availability of Data and Material Not applicable.

Code Availability Not applicable.

\section{Declarations}

Additional Declarations for Articles in Life Science Journals that Report the Results of Studies Involving Humans and/or Animals Not applicable. 
Ethics Approval Not applicable.

Consent to Participate Not applicable.

Consent for Publication LFD as sole author agrees to the submission and publication of the manuscript.

Conflict of Interest The author declare no conflict of interest or competing interests.

\section{References}

1. Calvo-Porral C, Lévy-Mangin J-P (2020) The Circular Economy Business Model: Examining Consumers' Acceptance of Recycled Goods. 10(2):28

2. LE Europe, et al., Behavioural Study on Consumers' Engagement in the Circular Economy, in Implementing Framework Contract - CHAFEA/2015/CP/01/LE, E. Comission, Editor. 2018.

3. Shahbazi, S. and A.K. Jönbrink, Design Guidelines to Develop Circular Products: Action Research on Nordic Industry. 2020. 12(9): p. 3679.

4. Rink DR, Swan JE (1979) Product life cycle research: a literature review. Journal of Business Research 7(3):219-242

5. Jørgensen S, Pedersen LJT (2018) The Circular Rather than the Linear Economy, in RESTART Sustainable Business Model Innovation. Springer International Publishing, Cham, pp 103-120

6. Blythe J (2009) Key Concepts in Marketing, in Key Concepts in Marketing, SAGE, Editor. SAGE Publications Ltd, London

7. Sariatli F (2017) Linear Economy Versus Circular Economy: A Comparative and Analyzer Study for Optimization of Economy for Sustainability. 6(1): p. 31

8. Garcés-Ayerbe C, Rivera-Torres P, Suárez-Perales I, Leyva-de la Hiz D (2019) Is it possible to change from a linear to a circular economy? An overview of opportunities and barriers for European small and mediumsized enterprise companies. International Journal of Environmental Research and Public Health 16(5):851

9. Moreno M, de los Rios C, Rowe Z, Charnley F (2016) A Conceptual Framework for Circular Design. Sustainability 8(9):937

10. Kirchherr J, Reike D, Hekkert M (2017) Conceptualizing the circular economy: an analysis of 114 definitions. Resources, Conservation and Recycling 127:221-232

11. Savini F (2019) The economy that runs on waste: accumulation in the circular city. Journal of Environmental Policy \& Planning 21(6):675-691

12. Group, T., et al. Regulatory barriers for the Circular Economy: lessons from ten case studies. 2016 [cited 2020 09/05/2020]; Available from: https:/ec.europa.eu/growth/content/regulatory-barriers-circulareconomy-lessons-ten-case-studies_en.

13. group, E.M. Building blocks. 2020 [cited 2020 09/05/2020]; Available from: https://www. ellenmacarthurfoundation.org/circular-economy/concept/building-blocks.

14. Houston, J., et al., Enablers and Barriers to a Circular Economy. 2019.

15. Ritchie, M. Actions for a circular economy in Australia from the EU model. 2019 [cited 2020 09/05/2020]; Available from: https:/www.insidewaste.com.au/index.php/2019/09/16/actions-for-a-circular-economy-inaustralia-from-eu-model/.

16. Gianmarco B, Marco P, Nicola S (2019) Assessing the impacts of circular economy: a framework and an application to the washing machine industry. International Journal of Management and Decision Making 18(3):282-308

17. Hobson, K., 'Small stories of closing loops': social circularity and the everyday circular economy. Climatic Change, 2019.

18. Ellsmoor, J. United States Spend Ten Times More On Fossil Fuel Subsidies Than Education. 2019 [cited 2020 09/05/2020]; Available from: https:/www.forbes.com/sites/jamesellsmoor/2019/06/15/united-statesspend-ten-times-more-on-fossil-fuel-subsidies-than-education/\#7325713f4473.

19. Mazengarb, M. Global fossil fuel subsidies reach $\$ 5.2$ trillion, and $\$ 29$ billion in Australia. 2019 [cited 2020 09/05/2020]; Available from: https://reneweconomy.com.au/global-fossil-fuel-subsidies-reach-5-2-trillionand-29-billion-in-australia-91592/.

20. Lee PT-W, Kwon OK, Ruan X (2019) Sustainability Challenges in Maritime Transport and Logistics Industry and Its Way Ahead. Sustainability 11(5):1331

21. Wu X, Zhang L, Luo M (2020) Current strategic planning for sustainability in international shipping. Environment, Development and Sustainability 22(3):1729-1747 
22. Kabongo JD (2013) Waste Valorization. In: Idowu SO et al (eds) Encyclopedia of Corporate Social Responsibility. Springer Berlin Heidelberg, Berlin, pp 2701-2706

23. Loizidou M (2016) Waste Valorization and Management. Waste and Biomass Valorization 7(4):645-648

24. Gaustad G, Krystofik M, Bustamante M, Badami K (2018) Circular economy strategies for mitigating critical material supply issues. Resources, Conservation and Recycling 135:24-33

25. PWC. Now and next: supply chain resilience measures for coronavirus. 2020 [cited 2020 09/05/2020]; Available from: https://www.digitalpulse.pwc.com.au/supply-chain-coronavirus-covid-19/.

26. Lieder M, Rashid A (2016) Towards circular economy implementation: a comprehensive review in context of manufacturing industry. Journal of Cleaner Production 115:36-51

27. Parida V, Burström T, Visnjic I, Wincent J (2019) Orchestrating industrial ecosystem in circular economy: a two-stage transformation model for large manufacturing companies. Journal of Business Research 101:715725

28. Virtanen, M., K. Manskinen, and S. Eerola (2017) Circular Material Library. An Innovative Tool to Design Circular Economy. Design J. 20

29. Valera-Medina A, Xiao H, Owen-Jones M, David WIF, Bowen PJ (2018) Ammonia for power. Progress in Energy and Combustion Science 69:63-102

30. Ng KS, Yang A, Yakovleva N (2019) Sustainable waste management through synergistic utilisation of commercial and domestic organic waste for efficient resource recovery and valorisation in the UK. Journal of Cleaner Production 227:248-262

31. Ghosh, P., et al., Chapter 7 - Biogas production from waste: technical overview, progress, and challenges, in Bioreactors, L. Singh, A. Yousuf, and D.M. Mahapatra, Editors. 2020, Elsevier. p. 89-104.

32. Issa, K., Recent Advances of Biogas Production and Future Perspective. 2021: p. - Ch. 1.

33. Maina JW, Pozo-Gonzalo C, Kong L, Schütz J, Hill M, Dumée LF (2017) Metal organic framework based catalysts for CO2 conversion. Materials Horizons 4(3):345-361

34. Vasudevan S et al (2019) Technoenergetic and Economic Analysis of CO2 Conversion. In: Aresta M, Karimi I, Kawi S (eds) An Economy Based on Carbon Dioxide and Water: Potential of Large Scale Carbon Dioxide Utilization. Springer International Publishing, Cham, pp 413-430

35. Mavukkandy MO, Chabib CM, Mustafa I, al Ghaferi A, AlMarzooqi F (2019) Brine management in desalination industry: from waste to resources generation. Desalination 472:114187

36. Pramanik BK, Shu L, Jegatheesan V (2017) A review of the management and treatment of brine solutions. Environmental Science: Water Research \& Technology 3(4):625-658

37. Perlmutter BA (1997) New techniques for solvent recovery and elimination of wastewater emissions during vacuum process operations. Environmental Progress 16(2):132-136

38. Liu C, Lin J, Cao H, Zhang Y, Sun Z (2019) Recycling of spent lithium-ion batteries in view of lithium recovery: a critical review. Journal of Cleaner Production 228:801-813

39. Markets, R.a. Analysis of the World's \$45.78Bn E-waste Management Market, 2019-2025. 2019 [cited 2020 09/05/2020]; Available from: https://www.prnewswire.com/news-releases/analysis-of-the-worlds-4578bn-e-waste-management-market-2019-2025\%2D\%2D300974594.html.

40. Ilankoon IMSK, Ghorbani Y, Chong MN, Herath G, Moyo T, Petersen J (2018) E-waste in the international context-a review of trade flows, regulations, hazards, waste management strategies and technologies for value recovery. Waste Management 82:258-275

41. Abdel-Shafy HI, Mansour MSM (2018) Solid waste issue: sources, composition, disposal, recycling, and valorization. Egyptian Journal of Petroleum 27(4):1275-1290

42. Calleja, D. Why the "New Plastics Economy" must be a circular economy. 2019 [cited 2020 09/05/2020]; Available from: https://journals.openedition.org/factsreports/5123.

43. Enfrin M, Dumée LF, Lee J (2019) Nano/microplastics in water and wastewater treatment processesorigin, impact and potential solutions. Water Research 161:621-638

44. Enfrin M, Lee J, Gibert Y, Basheer F, Kong L, Dumée LF (2020) Release of hazardous nanoplastic contaminants due to microplastics fragmentation under shear stress forces. Journal of Hazardous Materials 384: 121393

45. Kashani A, Ngo TD, Hajimohammadi A (2019) Effect of recycled glass fines on mechanical and durability properties of concrete foam in comparison with traditional cementitious fines. Cement and Concrete Composites 99:120-129

46. Imteaz MA, Ali MY, Arulrajah A (2012) Possible environmental impacts of recycled glass used as a pavement base material. Waste Management \& Research 30(9):917-921

47. Demiss BA, Oyawa WO, Shitote SM (2018) Mechanical and microstructural properties of recycled reactive powder concrete containing waste glass powder and fly ash at standard curing. Cogent Engineering 5(1): 1464877

48. Veasey TJ (1997) An overview of metals recycling by physical separation methods. Proceedings of the Institution of Mechanical Engineers, Part E: Journal of Process Mechanical Engineering 211(1):61-64 
49. Zhan L, Xu Z (2009) Separating and Recycling Metals from Mixed Metallic Particles of Crushed Electronic Wastes by Vacuum Metallurgy. Environmental Science \& Technology 43(18):7074-7078

50. Ali UM (2018) Electrochemical Separation and Purification of Metals from WEEE. LAP Lambert Academic Publishing

51. Hopewell J, Dvorak R, Kosior E (2009) Plastics recycling: challenges and opportunities. Philosophical transactions of the Royal Society of London Series B, Biological Sciences 364(1526):2115-2126

52. Vilaplana F, Karlsson S (2008) Quality Concepts for the Improved Use of Recycled Polymeric Materials: A Review. Macromolecular Materials and Engineering 293(4):274-297

53. Mativenga PT, Sultan AAM, Agwa-Ejon J, Mbohwa C (2017) Composites in a Circular Economy: A Study of United Kingdom and South Africa. Procedia CIRP 61:691-696

54. Koumoulos EP, Trompeta AF, Santos RM, Martins M, Santos CM, Iglesias V, Böhm R, Gong G, Chiminelli A, Verpoest I, Kiekens P, Charitidis CA (2019) Research and Development in Carbon Fibers and Advanced High-Performance Composites Supply Chain in Europe: A Roadmap for Challenges and the Industrial Uptake. Journal of Composites Science 3(3):86

55. Gustafsson AMK et al (2015) Investigation of an Electrochemical Method for Separation of Copper, Indium, and Gallium from Pretreated CIGS Solar Cell Waste Materials. The Scientific World Journal 2015:494015

56. Earley, R. and K. Goldsworthy. Designing for Fast and Slow Circular Fashion Systems: Exploring Strategies for Multiple and Extended Product Cycles. 2015 [cited 2020 09/05/2020]; Available from: https://core.ac.uk/display/30316652

57. Todor MP, Bulei C, Kiss I, Cioată VG (2019) Recycling of textile wastes into textile composites based on natural fibres: the reinforcement type and the architecture. IOP Conference Series: Materials Science and Engineering 477:012055

58. Yang Y, Boom R, Irion B, van Heerden DJ, Kuiper P, de Wit H (2012) Recycling of composite materials. Chemical Engineering and Processing: Process Intensification 51:53-68

59. Goldsworthy K, Earley R, Politowicz K (2018) Circular Speeds: A Review of Fast \& Slow Sustainable Design Approaches for Fashion \& Textile Applications. Journal of Textile Design Research and Practice 6: 42-65

60. Hall C (2018) MIXING IT UP IN PRATO: identifying innovation hotspots within mechanical textile recycling

61. WRAP. Reinvent, rethink and redefine what is possible. 2021 [cited 2021 19/05/2021]; Available from: https://wrap.org.uk/what-we-do/our-services.

62. Terracycle. Recycle Everything with Terracycle. 2021 [cited 2021 19/05/2021]; Available from: https:// www.terracycle.com/en-US/. 